\title{
PRELIMINARY DESIGN OF THE TOP CAP OF DEMO WATER-COOLED LITHIUM LEAD BREEDING BLANKET SEGMENTS
}

\author{
R. Forte ${ }^{a^{*}}$, P. Arena ${ }^{b}$, G. Bongiovìc, I. Catanzaro ${ }^{a}$, A. Del Nevo ${ }^{b}$, P.A. Di Maioa, E. Vallone ${ }^{a}$
}

aDepartment of Engineering, University of Palermo, Palermo, Italy

bENEA-FSN-ING-PAN, ENEA CR Brasimone, Camugnano, Italy

cKarlsruhe Institute of Technology (KIT), Institute for Neutron Physics and Reactor Technology (INR), Hermann-von-Helmholtz-Platz 1, 76344 EggensteinLeopoldshafen, Germany

(a) ruggero.forte@unipa.it

\section{Abstract}

Within the framework of EUROfusion R\&D activity, a research campaign has been carried out at the University of Palermo, in close cooperation with ENEA labs, in order to preliminary design the top cap foreseen for the DEMO Water-Cooled Lithium Lead (WCLL) breeding blanket segments. Due to the high heat and pressure loads acting on such component, its design results particularly demanding and a specific multi-physics approach is needed, covering several aspects from design to thermal-hydraulic and structural assessments. Preliminary detailed CAD model of the cap integrated into the upper region of the WCLL breeding blanket outboard central segment has been set-up, equipped with proper cooling circuits as well as manifold and attachment systems according to the design of the equatorial elementary cell. A detailed numerical model has been set-up with the aim of simulating both the thermal-hydraulic and thermo-mechanical behaviour of the above-mentioned system.

Finally, the thermo-mechanical response of the upper breeding blanket region has been evaluated in terms of stress and temperature distributions, verifying that the structura material maximum temperature stays below its limit value and that structural integrity is ensured by means of the fulfilment of design rules reported in RCC-MRx structural design code.

\section{Introduction}

The design of a Top Cap preliminary model is one of the most important issue in the WCLL BB R\&D activities, due to the high heat and pressure loads acting on such component. So, a research campaign has been performed at the University of Palermo and, due to the complexity of the geometry of the TC as well as to the non-uniform heat load distribution, a methodology based on a Design-by-Analysis approach has been followed. To this purpose, FEM model of the WCLL BB TC, equipped with a proper set of Double Walled Tubes (DWTs) aimed at cooling the Breeder Zone (BZ) and a set of square channels intended to refrigerate both FW and caps, has been set up and their thermo-mechanical performances have been investigated under Normal Operation (NO) and Over-Pressurization (OP) steady state loading scenarios. Finally, the proposed TC design structural integrity has been checked against the design criteria of RCC-MRx structural design code. A theoretical-numerical approach, based on the Finite Element Method (FEM) has been followed and a qualified commercial FEM code, ABAQUS v6.14, has been adopted.

\section{Outboard central segment Top Cap}

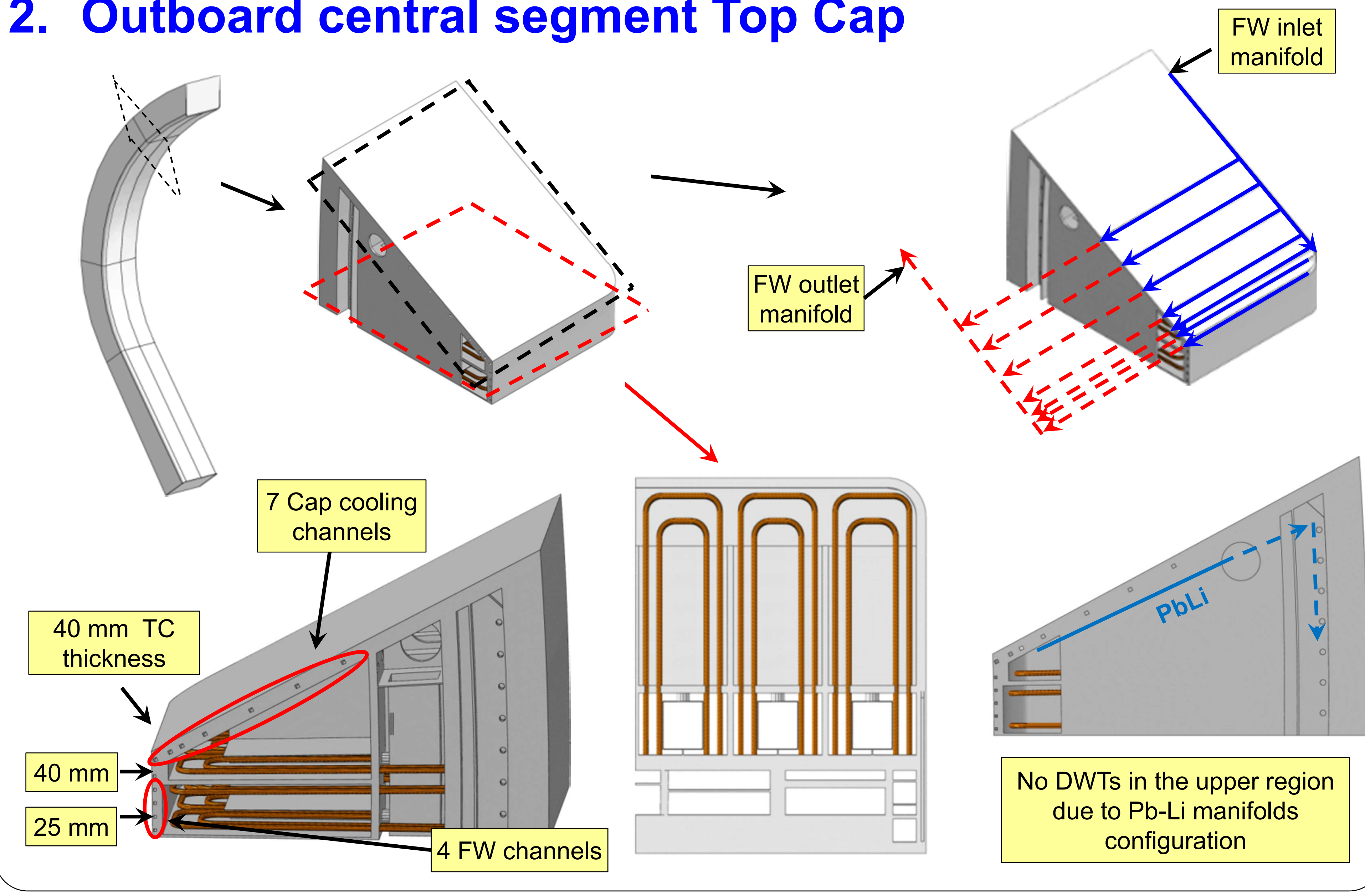

\section{Thermo-mechanical loads and boundary conditions}

A detailed geometric model composed of $\sim 2.8 \mathrm{M}$ nodes connected in $\sim 5 \mathrm{M}$ linear elements has been set up. Proper loads and boundary conditions have been applied in order to investigate its thermomechanical behaviou

Thermal loads and boundary conditions

Heat flux equal to $0.66 \mathrm{MW} / \mathrm{m}^{2}$ on the FW plasma facing surface

Non-uniform volumetric density of nuclear-deposited heat power derived from nuclear analyses

Convective heat transfer between SB cooling channels and DWTs internal walls with the water coolant;

Pure diffusive heat transfer within the breeder with a thermal conductance at the wetted wall equal to $10^{5} \mathrm{~W} / \mathrm{m}^{2 \circ} \mathrm{C}$.

Mechanical loads and boundary conditions

Pressure on the coolant-wetted surfaces (15.5 MPa and 18.6 $\mathrm{MPa}$, in $\mathrm{NO}$ and $\mathrm{OP}$ loading scenarios, respectively);

Pressure on the breeder-wetted surfaces $(0.5 \mathrm{MPa}$ and 18.6 $\mathrm{MPa}$, in $\mathrm{NO}$ and $\mathrm{OP}$ loading scenarios, respectively);

Strain load due to thermal expansion from thermal analysis

Mechanical restrains.

\section{Results}
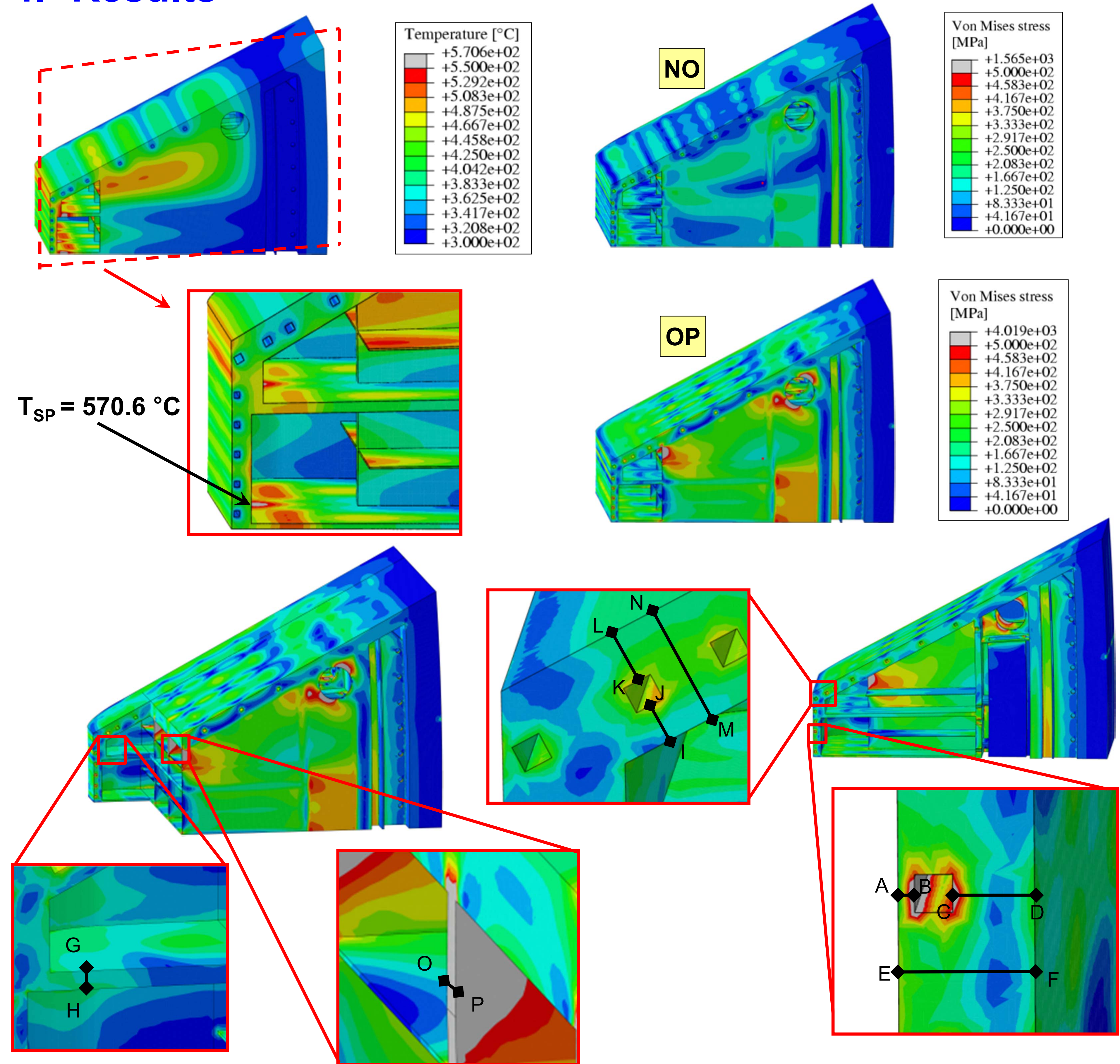

Steady state analysis of the Top Cap model set-up have been ru and a stress linearization procedure has been performed along 8 critical paths in order to verify the fulfilment of the design rules reported in the RCC-MRx code. All the Level A safety criteria are fulfilled along all paths taken into account, while, as regards Level $D$, two paths do not fulfil some criteria.

\begin{tabular}{|c|c|c|c|c|c|}
\hline & \multicolumn{5}{|c|}{ Low Temperature rules - Level D RCC-MRx criteria } \\
\hline Path & $T_{\text {Ave }}\left[{ }^{\circ} \mathrm{C}\right]$ & $\mathrm{P}_{\mathrm{m}} / \mathrm{S}_{\mathrm{m}}\left(\mathrm{P}_{\mathrm{m}}+\mathrm{P}_{\mathrm{b}}\right) / \mathrm{K}_{\text {eff }} \mathrm{S}_{\mathrm{m}}\left(\mathrm{P}_{\mathrm{m}}+\mathrm{Q}_{\mathrm{m}}\right) / \mathrm{S}_{\mathrm{e}}\left(\mathrm{P}_{\mathrm{m}}+\mathrm{P}_{\mathrm{b}}+\mathrm{Q}+\mathrm{F}\right) / \mathrm{S}_{\text {et }}$ \\
\hline AB & 376.43 & 1.06 & 0.84 & 1.06 & 0.26 \\
\hline CD & 373.86 & 0.43 & 0.55 & 0.33 & 0.24 \\
\hline EF & 453.97 & 0.40 & 0.42 & 0.40 & 0.13 \\
\hline GH & 437.55 & 0.37 & 0.25 & 0.49 & 0.07 \\
\hline IJ & 430.47 & 0.75 & 0.52 & 0.62 & 0.15 \\
\hline KL & 338.22 & 0.34 & 0.37 & 0.59 & 0.14 \\
\hline MN & 411.11 & 0.32 & 0.28 & 0.55 & 0.08 \\
\hline OP & 503.82 & 1.40 & 0.94 & 1.38 & 0.22 \\
\hline
\end{tabular}

\section{Conclusions}

Within the framework of the DEMO R\&D activities, a research campaign has been carried out at University of Palermo to investigate thermo-mechanical performances of a preliminary design of the Top Cap of the WCLL OBC segment. From the thermal point of view, results obtained show that an acceptable temperature distribution is reached within structure with the exception of the SPs, where temperature exceeds the maximum allowable value of $550{ }^{\circ} \mathrm{C}$. As far as the mechanical behaviour is concerned, the selected thickness of the TC allows it to withstand mechanical loads while, with regard to the SB, some regions of the FW and the vertical SP do not fulfil the considered criteria in the OP scenario. The promising results obtained lead to the conclusion that a further development of the work in needed. The aim is to investigate a more detailed nuclear heating distribution and to optimize the BZ cooling circuit layout in order to improve the TC thermal-mechanical behaviour. 